\title{
Preparative gradient chromatography *
}

\author{
Andreas Seidel-Morgenstern ${ }^{1,2}$ \\ ${ }^{1}$ Institut für Verfahrenstechnik, Otto-von-Guericke-Universität, Universitätsplatz 2, D-39106 Magdeburg, Germany \\ ${ }^{2}$ Max-Planck-Institut für Dynamik komplexer technischer Systeme, Sandtorstr. 1, D-39106 Magdeburg, Germany \\ (email: anseidel@vst.uni-magdeburg.de)
}

\begin{abstract}
It is convenient to keep during a chromatographic separation the essential operating parameters like temperature, pressure, mobile phase flowrate and mobile phase composition constant. In contrast it is well known that in contrast to this isocratic operation an intelligent modulation of certain operating parameters can improve the separation performance significantly. Such gradient approaches are widely applied in analytical (linear) chromatography to reduce the time of analysis and to enhance the selectivity. In contrast, the extent of applying gradients is still rather limited in the field of preparative (nonlinear) chromatography. The first part of this paper is devoted to discuss principal differences between linear and nonlinear and between isocratic and gradient chromatography. The second part focuses on introducing a countercurrent process that allows performing separations in a continuous manner exploiting efficiently a two-step solvent composition gradient.
\end{abstract}

* Extended version of a paper that was recently published on the occasion of "100 years chromatography" in Russian (Seidel-Morgenstern, 2003). 


\section{Introduction}

Besides applying chromatography as an analytical technique there is a growing interest in the pharmaceutical industry and in biotechnology to isolate and purify efficiently value added products using preparative liquid chromatography (Ganetsos and Barker, 1993).

In contrast to the small sample sizes that are processed for analysis, larger injection concentrations or volumes are relevant in a preparative scale. Under these conditions the underlying distribution equilibria are not linear anymore and competition effects have to be taken into account. The most essential feature related to column overloading is the fact that the retention times become concentration dependent (Guiochon et al, 1994).

Since in an industrial scale simple and reliable regimes are preferred, separation processes with a preparative purpose are often performed using isocratic elution chromatography. This means that during the process all operating conditions are kept constant with the exception of the periodic changes of injecting at the column inlet the feed or the mobile phase. Thus, an analysis and the design of the separation processes rely typically on nonlinear but fixed thermodynamic functions. However, often the retention behavior of the components in a mixture to be treated varies in a broad range and it is attractive to modulate certain process conditions during the process, e.g. in order to speed up slowly migrating components (Snyder, 1968, Jandera and Churacek, 1985). Such a gradient operation allows to inject samples more frequently and to increase the overall process productivity. In addition there might be further favorable effects of gradients compared to isocratic operation related to the potential of enhancing the product concentrations (Felinger and Guiochon, 1996 and 1998, Jandera et al. 1998, Nagrath et al. 2005).

For preparative purposes it is in addition very attractive to substitute the discontinuous regime of elution chromatography by a continuous operation. In particular successful is the simulated moving bed (SMB) process suggested more then fourty years ago by Broughton and Gerhold (1961). This approach exploits a countercurrent between the mobile and stationary phases. After the SMB process was initially applied mainly in the petroleum and sugar industries (Ganetsos and Barker, 1993) it conquered in the last decade the pharmaceutical industry where it is now frequently applied for enantioseparations (e.g. Nicoud, 1998). A feature of the 
conventional four zone SMB process is its isocratic character. However, recently several suggestions were made to further improve the performance of SMB chromatography by implementing various types of gradients (e.g. Clavier et al., 1995, Mazzotti et al. 1997a, Depta et al., 1999, Jensen et al., 2000, Antos and SeidelMorgenstern 2001, Abel et al. 2002 and 2004 , Howing et al. 2002 and 2003).

\section{Analytical versus preparative chromatography}

Essential differences between analytical and preparative elution chromatography were comprehensively summarized by Guiochon et al. $(1994,2002)$.

To illustrate some important aspects it is instructive to use a simple model describing main features of band propagation in chromatographic columns. Fixed-beds which are well packed with small particles could adequately be described using the equilibrium dispersion model. In this model all effects causing band broadening are lumped into an apparent dispersion coefficient, $D_{a p p}$, which is closely related to the number of theoretical plates, $N$. The corresponding mass balance for a component $i$ in a mixture of $K$ components is:

$$
\frac{\partial c^{i}}{\partial t}+\frac{1-\varepsilon}{\varepsilon} \frac{\partial q^{i}\left(c^{1}, c^{2}, \ldots, c^{K}\right)}{\partial t}+u \frac{\partial c^{i}}{\partial z}=D_{a p p}^{i} \frac{\partial^{2} c^{i}}{\partial z^{2}} \quad \text { for } \quad i=1, \ldots, K
$$

with

$$
D_{\text {app }}^{i}=\frac{u L}{2 N^{i}}
$$

In the above $\varepsilon$ is the total column porosity, $u$ is the linear velocity of the mobile phase and $L$ is the column length. Most essential are the equilibrium functions relating the loading of a component $i, q^{i}$, to the fluid phase concentrations of all components, $c^{1}$, $c^{2}, \ldots, c^{K}$. In order to use the above model for simulations of separation processes the typically nonlinear functions $q^{i}=q^{i}\left(c^{1}, c^{2}, \ldots, c^{K}\right)$ must be provided. To predict a specific process regime, in addition, the corresponding initial and boundary conditions need to be specified. In elution chromatography the stationary phases are often considered to be initially completely regenerated and rectangular injection profiles are assumed. 
The system of mass balance equations given with eq. 1 can be solved numerically using e.g. standard finite difference methods after appropriate discretization (e.g. Lapidus and Pinder, 1982, Guiochon et al., 1994).

The Multi-Langmuir equation is widely used to describe the equilibrium due to its simplicity and capability of fitting many experimental results (Guiochon et al., 1994, Nicoud and Seidel-Morgenstern, 1996):

$$
q^{i}=\frac{a^{i} c^{i}}{1+\sum_{j=1}^{K} b^{j} c^{j}} \quad i=1, \ldots, K
$$

The parameters $a^{i}$ are the Henry constants and the parameters $b^{i}$ are related to the specific adsorption energies. For very low concentrations eq. 3 reduces to the linear Henry law:

$$
q^{i}=a^{i} c^{i} \quad i=1, \ldots, K
$$

In analytical chromatography instead of the Henry constants $a^{i}$ often the capacity factors $k^{\prime} i$ are used which are defined as:

$$
k^{\prime}{ }^{i}=\frac{1-\varepsilon}{\varepsilon} a^{i} \quad i=1, \ldots, K
$$

Solving eqs. 1-3 typical features of linear and nonlinear chromatography can be explained. Fig. 1 illustrates the well known impact of the plate number $N$ (or the apparent dispersion coefficient $D_{\text {app}}$ ) on the variance of the bands in analytical chromatography. Fig. 2 reveals that under nonlinear conditions often the plate numbers or efficiencies loose importance and thermodynamics start to influence more strongly band shapes and retention times. The impact of column efficiency is typically less important under overloaded conditions. The aspect of competition, relevant under nonlinear conditions, is exemplified in Figs. 3 and 4 where simulated elution profiles are compared for injecting the same amount of a component alone or in a mixture with another component. The two effects that can be observed are known as "displacement effect" (Fig. 3) and "tag along effect" (Fig. 4). Results of further systematic parametric studies with the equilibrium dispersion model can be found elsewhere (e.g. Guiochon et al., 1994, Seidel-Morgenstern, 1995). 
To conclude this section it should be emphasized that the knowledge of the nonlinear and competitive equilibrium functions is the main prerequisite for a quantitative prediction of chromatographic band profiles under overloaded conditions.

\section{Isocratic versus gradient chromatography}

In contrast to the isocratic operation regime where all parameters are kept constant, it is often very attractive to modulate certain parameters during the separation process. Parameters that influence the migration speeds of concentration fronts in chromatographic columns are e.g. the temperature, the pressure, the flowrate and the composition of the mobile phase. In liquid chromatography the latter includes the frequently applied pH and ionic strength gradients. Due to the availability of accurate gradient pumps, the mobile phase composition can be flexible and accurately altered during the separation process.

Conceivable gradient shapes are illustrated schematically in Fig. 5. Typical effects of using gradients are illustrated in Fig. 6 based on results of a theoretical optimization study (Shan and Seidel-Morgenstern, 2005). Considered was the separation of a ternary mixture where the second eluting component was the target component. $A$ product of productivity and yield was maximized using the injection conditions and the solvent composition as the free parameters. Fig. 6a presents the isocratic situation as the reference case, where the optimal fraction of the stronger component in a binary solvent was found to be 22 vol\%. The consequence of using an optimized slightly nonlinear gradient between 5 and 50 vol\% is shown in Fig. 6b. The gradient operation allows reducing retention times, sharpening the peaks and increasing product concentrations.

It should be mentioned that the optimization of gradient shapes is a challenging task. The results usually strongly depend on the objective function provided. Important aspect of this problem have been treated e.g. by Truei et al. (1992), Gallant et al. (1995 and 1996), Felinger and Guiochon (1996 and 1998), Spieker et al. (1998), Jandera (1998 and 1999), Nikitas and Pappa-Louisi (2005) and Nagrath et al. (2005). In order to quantify chromatographic processes using solvent strength gradients it is necessary to quantify the effect of the modifier on the course of the equilibrium functions. Several models have been suggested that describe the relation between 
the concentration of a modifier present in the solvent (characterized e.g. by its amount in volume percent, $c^{\text {mod }}$ ) and the capacity factors, $k^{\prime}$, using functions of the following types:

$$
\begin{aligned}
& \log k^{\prime}=\alpha-\beta \log c^{\text {mod }} \\
& \log k^{\prime}=\alpha-\beta c^{\text {mod }} \\
& \log k^{\prime}=\alpha-\beta \log c^{\text {mod }}+\gamma c^{\text {mod }} \\
& \log k^{\prime}=\alpha+\beta c^{\text {mod }}+\gamma c^{\text {mod }}{ }^{2}+\ldots \\
& k^{\prime}=\alpha+\beta c^{\text {mod }}+\gamma c^{\text {mod }^{2}}+\ldots
\end{aligned}
$$

The interpretation and correlation of the parameters in the above equations has been studied extensively both for reverse phase and normal phase systems (e.g. Snyder, 1968, Socewinski, 1969, Horvath et al., 1976, Jandera and Churacek, 1985, Snyder and Stadelius, 1986, Jandera 1999 and 2003, Wang and Carr, 2002, Snyder at al. 2004).

The situation becomes more complex if the effect of the modifier concentration needs to be quantified for nonlinear isotherms. Often the impact of the modifier is implemented more or less empirically keeping the structure of a nonlinear isotherm model which was found applicable to describe the isocratic situations. Then the same type of correlations given by eqs. $6-10$ is used to describe parameters contained in this model (e.g. Jandera 1998, Gritti et al, 2003). For the Langmuir model given above this approach leads to the following model equation:

$$
q^{i}=\frac{a^{i}\left(c^{\text {mod }}\right) c^{i}}{1+\sum_{j=1}^{K} b^{j}\left(c^{\text {mod }}\right) c^{j}} \quad i=1, \ldots, K
$$

Assuming e.g. the applicability of eq. 6 for both $a^{i}$ and $b^{i}$ the impact of $c^{\text {mod }}$ can be described after introducing empirical parameters $a_{1}^{i}, a_{2}^{i}, b_{1}^{i}$ and $b_{2}^{i}$ in the following manner:

$$
a^{i}\left(c^{\text {mod }}\right)=\left(a_{1}^{i} c^{\text {mod }}\right)^{-a_{2}^{i}} \quad \text { and } b^{i}\left(c^{\text {mod }}\right)=\left(b_{1}^{i} c^{\text {mod }}\right)^{-b_{2}^{i}}
$$


Thermodynamically more sound approaches are based on considering in the analysis also all constituents of the solvent (e.g. Jandera et al. 1999). Typically it is attempted to introduce thermodynamically consistent activity coefficients describing the non ideality of the liquid and/or adsorbed phases. Promising suggestions in this direction are based e.g. on using the real adsorbed solution theory (Myers, 1983). Unfortunately for real separation problems the required activity coefficients are usually not available and must be determined in tedious experimental investigations. For various chromatographic systems quantitative descriptions of overloaded gradient elution bands have been presented, e.g. by Antia and Horvath (1989), Yamamoto et al. (1993), Gallant et al. (1995 and 1996), El Fallah and Guiochon (1996), Mihlbachler et al. (1998), Gueorguieva et al. (2002), Jandera (2002) and Gritti et al. (2003).

\section{Batch versus continuous chromatography}

In analytical chromatography the discontinuous elution mode (batch chromatography) is usually the method of choice. To process larger numbers of samples in an efficient manner the reduction of the separation time is a key issue. In a repetitive injection mode typically the next feed sample is already dosed before complete elution of the previous injection. Nevertheless the stationary phase is often not efficiently exploited and in preparative chromatography there is a strong interest in more productive continuous separation modes.

Among the alternatives currently available in particular attractive is the so-called simulated moving bed (SMB) process. The principle is best explained introducing the hypothetical process of the true moving bed (TMB). The basic idea is to arrange in the column a countercurrent between the solid and fluid phases as sketched in Fig. 7. The feed $(F)$, containing e.g. the two components $A$ and $B$, is introduced in the middle of this unit. Provided the flowrates of the two phases are adjusted properly and a separation takes place in the indicated zones II and III, a regime can be established allowing to collect continuously the less adsorbable component $A$ upstream at the raffinate port $(R)$ and the more adsorbable component $B$ downstream at the extract port $(E)$. In order to use the two recirculating phases most 
economically it is expedient to guarantee a complete regeneration in the two zones I and IV. This requires as a second input stream the introduction of a desorbent (D). Several models have been developed to study this countercurrent process and nowadays reliable design and optimization tools are available (Ruthven and Ching, 1989, Ganetsos and Barker, 1993, Mazzotti et al., 1997b, Migliorini et al., 1998, 1999). In particular simple are models describing the process as a series connection of equilibrium stages (e.g. Beltscheva et al., 2003). The mass balance of component $i$ for a single equilibrium stage $j$ (which is a part of the unit illustrated in Fig. 7 ) is:

$$
\begin{aligned}
& \dot{V}_{S} q_{j-1}^{i}\left(\bar{c}_{j-1}^{i}\right)+\dot{V} c_{j+1}^{i}-\dot{V} c_{j}^{i}-\dot{V}_{S} q_{j}^{i}\left(\bar{c}_{j}^{i}\right)=\dot{V}_{\text {ext }} c^{\text {ext }} \\
& \text { with } \quad \dot{V}_{\text {ext }} c^{\text {ext }}= \begin{cases}-\dot{V}_{F} c_{F}^{i} & \text { for } j=F \\
-\dot{V}_{D} c_{D}^{i} & \text { for } j=D \\
\dot{V}_{R} c_{R}^{i} & \text { for } j=R \\
\dot{V}_{E} c_{E}^{i} & \text { for } j=E \\
0 & \text { for all other } j\end{cases}
\end{aligned}
$$

The solution of the usually large system of coupled equations given by eq. $13(j=1$, $N_{\text {total }}$ requires typically the application of numerical methods.

An important requirement for a successful application of such a countercurrent process is to find the right flowrates. These are the four fluid phase flowrates $\dot{V}_{F}, \dot{V}_{D}, \dot{V}_{E}$ and $\dot{V}_{R}$ (that are related via the mass balances to the internal flowrates $\dot{V}_{l}, \dot{V}_{I l}, \dot{V}_{I I I}$ and $\dot{V}_{I V}$ ) and the solid phase flowrate $\dot{V}_{S}$. There is a powerful tool available to specify appropriate flowrates which is based on the equilibrium theory. This approach neglects all mass transfer resistances and assumes the hypothetical situation of an infinite number of equilibrium stages. An elegant analysis is based on specifying dimensionless flowrates (Mazzotti et al., 1997b, Migliorini et al., 1998, 1999):

$$
m_{z}=\frac{\dot{V}_{z}}{\dot{V}_{S}} \quad z=I, I I, I I I, I V
$$

There are certain bound for these flowrate ratios that need to be fulfilled in order to achieve a complete separation of the feed. For the simplifying situation of linear 
isotherms these bound are related just to the corresponding Henry constants of the feed components $A$ and $B$ as follows:

$$
\begin{aligned}
& m_{I V}<a^{A} \\
& a^{A}<m_{I I}<m_{I I I}<a^{B} \\
& a^{B}<m_{l}
\end{aligned}
$$

The obvious drawback of the described hypothetical true moving bed process is the difficulty of arranging the continuous movement of the solid phase. Thus, in reality a series connection of several fixed-beds is used. This simulated moving bed (SMB) process is illustrated in Fig. 8. By discrete shifting the positions for the feed and desorbent inputs and the raffinate and extracts output in the direction of the fluid phase flow the countercurrent of the true moving bed process is mimicked. For higher column numbers the TMB and SMB processes become equivalent.

Nowadays the simulated moving bed process is known to be a very powerful separation technology offering the possibility to separate continuously a feed stream into two product streams. Up to now the process is usually performed under isocratic conditions. Keeping this character there are several activities to further improve the performance by implementing asynchronous shift strategies (Ludemann et al., 2000) and modulating certain process parameters during the shift periods (e.g. Schramm et al., 2002, Zang and Wankat, 2002, Zhang et al. 2004).

\section{Principle of two-step gradient SMB chromatography}

Currently there are intensive efforts to exploit the potential of applying gradients in SMB processes. First activities have been devoted to study pressure gradients for SMB processes using a supercritical mobile phase. A stepwise modulation of the pressures in the four zones allows to optimize the local solvent strengths (Clavier et al., 1995, Nicoud et al., 1995, Mazzotti et al. 1997a, Depta et al., 1999). Later the simpler approach of using two differently composed liquid mobile phases for the feed and for the desorbent was studied theoretically and experimentally (Jensen et al., 2000, Antos and Seidel-Morgenstern 2001, Abel et al., 2002 and 2004, Houwing et al., 2002 and 2003, Wekenborg et al. 2004). 
The concept behind the two-step gradient SMB process is illustrated in Fig. 9. To introduce useful gradient conditions it is expedient to set the modifier concentration in the desorbent stream higher than that in the feed stream, i.e. $c_{D}{ }^{\text {mod }}>C_{F}{ }^{\text {mod }}$. As a result the two regeneration zones of the unit $(z=I$ and $z=I V$ ) work more efficiently and less desorbent is required. This offers the potential to obtain increased product concentrations. An aspect that needs to be considered is the fact that the modifier concentrations in the two outlet streams, $c_{E}{ }^{\text {mod }}$ and $c_{R}{ }^{m o d}$, will differ from each other and from the compositions of the feed streams. The design and optimization of such a two step-step gradient SMB process is complex and will not be described here. Details were given by e.g. Mazzotti et al. (1997a), Antos and Seidel-Morgenstern (2001, 2002b) and Abel et al. (2002).

In Fig. 10 are depicted for illustration a few results of simulating a two-step gradient countercurrent process for different flowrate ratios $m_{I I}$ and $m_{I I I}$ using the simplified equilibrium stage model given with eq. 13. It is obvious that the internal concentration profiles as well as the outlet concentrations (at the axial positions 0.25 and 0.75 ) strongly depend on the chosen operating conditions. Most noteworthy is the possible enrichment that can be achieved with this process (compare the outlet concentrations with the feed concentrations given as a dashed line). The complete parameter sets used for these calculations are given by Beltscheva et al. (2003).

\section{Experimental}

\subsection{System and model parameters}

Below a few selected experimental results will be presented to illustrate certain aspects related to preparative gradient chromatography in general and to two-step gradient SMB chromatography in particular. More details can be found in Gueorguieva et al. (2002), Antos and Seidel-Morgenstern, (2001, 2002a) and Beltscheva (2004).

The separation of binary mixtures of cyclopentanone (C5) and cycloheptanone (C7) was studied on a normal phase silica as the adsorbent $\left(d_{\text {pore }}=120 \AA\right.$, YMC Silica, 
Schermbeck, Germany). Eight columns of a Set $1\left(d_{\text {par }}=20 \mu \mathrm{m}, L=100 \mathrm{~mm}, d=6 \mathrm{~mm}\right)$ and four columns of a Set $2\left(d_{p a r}=12 \mu \mathrm{m}, L=250 \mathrm{~mm}, d=20 \mathrm{~mm}\right)$ were available.

As the mobile phase mixtures of n-hexane and ethyl acetate were used. Ethyl acetate acts as a modifier and can be used to alter the retention behavior.

To carry out various types of experiments at ambient temperature a conventional analytical HPLC unit (HP 1100, Agilent/Waldbronn, Germany) was available as well as a SMB unit (Prochrom/NovaSep, France) and a multifunctional valve that could be connected in a flexible manner with one or several columns, pumps and detectors (Knauer, Berlin, Germany).

In preliminary experiments the porosities and plate numbers of all columns were estimated analyzing the results of conventional pulse experiments. The following averaged values were obtained: $\varepsilon=0.79$ and $N=850$.

To determine the adsorption isotherms a perturbation method as described by Blümel et al. (1999) was applied. In Fig. 11 are shown the determined isotherms for the two components at three different levels of the modifier concentration. The obtained equilibrium data were analyzed using eqs. 11 and 12. The free parameters obtained from fitting theoretical to experimental isotherms are given in Table 1. Fig. 12 illustrates the impact of the ethyl acetate concentration on the two Henry constants. C5 is better adsorbable then C7. The presence of the modifier reduces the adsorbability of both components significantly.

\subsection{Discontinuous modes}

The effect of a linear gradient is illustrated in Fig. 13. In all experiments the same concentrated sample of $C 5$ and $C 7 \quad\left(c^{C 5}{ }_{I n j}=c^{C 7}{ }_{I n j}=40\right.$ vol\%) was injected in one column of Set 1. For the sake of comparison at first two isocratic situations (for $c^{\text {mod }}=5$ vol\% and 15 vol\%) were analyzed (solid lines). In agreement with the courses of the isotherms the higher modifier content reduced the retention times. Then two linear gradients (between modifier concentrations of 5 and 15 vol\%) were imposed with different steepnesses starting immediately after the completion of the sample injection. Obviously the gradient change significantly the band shapes. Steeper gradient lead to more pronounced acceleration effects. 
To enhance the productivity of a separation process it is attractive to apply multicolumn arrangement under gradient conditions. For this reason 4 columns of Set 2 were arranged in parallel at the moveable part of the multifunctional valve. By rotating at discrete times the valve (and thus the columns) a four-step gradient could be arranged. Combining the fixed ports of the valve with four pumps the modifier concentration levels and the flowrates could be altered in each step. After four steps each column returned to their initial position and a periodic pattern develops. Such an arrangement allows to introduce permanently feed. A comparison between experimentally determined elution profiles and predictions based on describing the isotherms with eqs. 11 and 12 is summarized in Fig. 14. More details are given elsewhere (Antos and Seidel-Morgenstern, 2002a).

\subsection{Continuous two-step gradient SMB chromatography}

Finally some results of studying the two-step gradient SMB process will be presented. Experiments were carried out using 8 columns of Set 1 with the Prochrom/NovaSep unit and four columns of Set 2 connected in series using the multifunctional valve.

For the experiments with the 8 columns of Set 1 two mobile phase compositions were prepared containing 15 vol\% and 35 vol\% of modifier. In a series of gradient experiments the feed mixture $(C 5: C 7=1: 1)$ was introduced in the unit with the weaker solvent $\left(c_{F}^{\text {mod }}=15\right.$ vol\%) whereas the stronger solvent was introduced at the desorbent position $\left(c_{D}^{\text {mod }}=35\right.$ vol\%). Fig. 15 shows the impact of varying the dimensionless flow rate in zone II, $m_{l l}$, by changing the solid phase flowrate (i.e. the shifting time). Obviously for values of $m_{\| /}$around 2.5 quite high purity can be obtained with the two-step gradient SMB process for both exctract and raffinate outlet streams. Similar as in isocratic SMB processes, $m_{l l}$ values above a certain threshold value lead to a reduction of the raffinate purity whereas lower values cause a reduction of the extract purity. For comparison in Fig. 15 are shown also results of two isocratic SMB runs at $m_{l l}=2.47$ with $c_{F}{ }^{\text {mod }}=c_{D}{ }^{\text {mod }}=15 \mathrm{vol} \%$ and $c_{F}{ }^{\text {mod }}=c_{D}{ }^{\text {mod }}=35 \mathrm{vol} \%$. The same operating parameters were used as for the corresponding two-step gradient experiment. The different internal modifier composition levels reduce drastically the outlet purity. Whereas for a constant modifier concentration of 35 vol\% still the 
correct orientation of the two components towards the respective collecting port is maintained, for 15 vol\% the "wrong" component appears at the raffinate port. These tendencies agree well with the results of predictions (Beltscheva, 2004).

In another experiment with 4 columns of Set 2, the most simple and also most attractive situation of using 0 and 100 vol\% of modifier in the two inlet streams was studied (Antos and Seidel-Morgenstern, 2001). The operating parameters applied and the results achieved under cyclic steady state conditions are summarized in Table 2. The purity of the two outlets as well as the high product concentrations (enrichments) confirmed the expectations based on preliminary simulations using eqs. 1, 11 and 12. To compare the results, in Table 2 are also given the corresponding features of an isocratic process operated at a modifier concentration level of 15 vol\%. Most noteworthy are the considerable reduction in the overall solvent consumption and the achieved enrichments in the product streams applying the two-step gradient process.

\section{Conclusions}

Solvent gradients are a powerful tool to improve the productivity in preparative liquid chromatography. The knowledge of the impact of a solvent composition modulation on the course of the adsorption isotherms of the components to be separated is the key for a quantitative understanding and design of suitable chromatographic processes. In this area there is still a lot of research work required in order to understand and predict such equilibria adequately. There are currently different attractive modes of gradient operation available. In particular the continuous simulated moving bed process might be further improved by introducing gradients. A simple concept is offered by implementing two-step gradients.

\section{Acknowledgement}

The contributions to this paper by Prof. Dorota Antos, Dr. Daria Beltscheva, Dipl.-Ing. Ludmila Gueorguieva and Dr. Yichu Shan are gratefully acknowledged. The author is also grateful for the support of Schering AG (Berlin, Germany), Knauer (Berlin, Germany) and Fonds der Chemischen Industrie. 


\section{References}

Abel S., Mazzotti M., Morbidelle M. (2002), Solvent gradient operation of simulated moving beds. I. Linear isotherms, J. Chromatogr. A, 944/1-2, 23

Abel S., Mazzotti M., Morbidelle M. (2004), Solvent gradient operation of simulated moving beds. II. Langmuir, J. Chromatogr. A, 1026, 47

Antia F. D., Horvath C. (1989), Gradient elution in nonlinear preparative liquid chromatography, J. Chromatogr., 483, 63

Antos D., Seidel-Morgenstern A. (2001), Application of gradients in the simulated moving bed process, Chem. Eng. Sci., 56, 6667

Antos D., Seidel-Morgenstern A. (2002a), Continuous step gradient elution for preparative separations, Sep. Sci. Techn., 37, 1469

Antos D., Seidel-Morgenstern A. (2002b), Two step solvent gradients in simulated moving bed chromatography - numerical study for linear equilibria, J. Chromatogr. $A$, 944/1-2, 77

Beltscheva D., Hugo P., Seidel-Morgenstern A. (2003), Linear two-step gradient countercurrent chromatography - analysis based on a recursive solution of an equilibrium stage model, J. Chromatogr. A, 989, 31

Beltscheva D. (2004), Ph.D. thesis, Otto-von-Guericke-Universität Magdeburg, Theoretische und experimentelle Studie der Gradienten-Gegenstromchromatographie

Blümel C., Hugo P., Seidel-Morgenstern A. (1999) Quantification of single solute and competitive adsorption isotherms using a closed-loop perturbation method, $\mathrm{J}$. Chromatogr. A, 865, 51

Broughton, D. B. and Gerhold, C. G. (1961), Continuous sprption process employing fixed bed of sorbent and moving inlets and outlets, U. S. Patent 2985589

Clavier J.Y., Nicoud R.M. Perrut, M. (1995), A new efficient process: the Simulating Moving Bed with supercritical eluent, in: High pressure Chemical Engineering, Elsevier Science, London, 429

Depta, A., Giese, T., Johannsen, M., Brunner, G. (1999) Separation of stereoisomers in a SMB-SFC Plant, J. Chromatog. A, 865, 175

El Fallah Z., Guiochon G. (1992), Prediction of protein band profile in preparative revere phase gradient elution, Biotechnol. Bioeng., 39, 877

Felinger A., Guiochon G. (1996), Optimizing experimental conditions in overloaded gradient elution chromatography, Biotechnol. Prog., 12, 638

Felinger A., Guiochon G. (1998), Comparing the optimum performance of the different modes of preparative liquid chromatography, J. Chromatogr. A., 12, 638

Gallant S.R., Kundu A., Cramer S. M. (1995), Optimization of step gradient separations: consideration of nonlinear adsorption, Biotechnol. Bioeng., 47, 355 
Gallant S.R., Vunnum S., Cramer S. M. (1996), Optimization of preparative ionexchange chromatography of proteins: linear gradient separations, J. Chromatogr. A., 725, 295

Ganetsos G., Barker P. E. (Eds.) (1993), Preparative and production scale chromatography, Marcel Dekker, New York

Gritti F., Feliner A., Guiochon G. (2003), Overloaded gradient elution chromatography on heterogeneous adsorbents in reversed-phase liquid chromatography, J. Chromatogr. A., 1017, 45.

Gueorguieva L., Beltscheva D., Antos D., Seidel-Morgenstern A. (2002), Adsorption from solvent mixtures with varying composition, in: Fundamentals of Adsorption 7 (Editors: Kaneko K., Kanoh H., Hanzawa Y.), IK International, Chiba-City, Japan, 1070

Gueorguieva L. (2005), Ph.D. thesis, Otto-von-Guericke-Universität Magdeburg, Präparative Gradientenchromatographie, in preparation

Guiochon, G., Golshan-Shirazi, S., Katti, A.M. (1994), Fundamentals of preparative and nonlinear chromatography, Academic Press, Boston

Guiochon G. (2002), Preparative liquid chromatography, J. Chromatogr. A., 965, 129

Horvath C., Melander W., Molnar I. (1976), Solvophobic interactions in liquid chromatography with nonpolar stationary phases, J. Chromatogr., 125, 129

Houwing J., Billiet H.A.H., van der Wielen L.A.M. (2002a), Optimization of azeotropic protein separation in gradient and isocratic ion-exchange simulated moving bed chromatography, J. Chromatogr. A., 944, 189

Houwing J., van Hateren S.H., Billiet H.A.H., van der Wielen L.A.M. (2002b), Titel, J. Chromatogr. A., 952, 85

Houwing J., Jensen S.H., van Hateren S.H., Billiet H.A.H., van der Wielen L.A.M. (2003), Titel, AlChE J., 49, 665

Jandera, P., Churacek, J. (1985) Gradient elution in column liquid chromatography, Elsevier, Amsterdam

Jandera P., Komers D., Guiochon G., (1998), Optimization of the recovery yield and the production rate in overloaded gradient-elution reversed-phase chromatography, J. Chromatogr. A., 796, 115

Jandera P. (1999), Simultaneous optimization of gradient time, gradient shape and initial composition of the mobile phase in the high performance liquid chromatography of homologous and oligomeric series, J. Chromatogr. A., 845, 133

Jandera P. (2002), Gradient elution in normal-phase high performance liquid chromatographic systems, J. Chromatogr. A., 965, 239

Jensen, T.B., Reijns, T.G.P., Billiet, H.A.H., van der Wielen, L.A.M. (2000) Novel simulated moving-bad method for reduced solvent consumption, J. Chromatogr. A, 873,149 
Lapidus, L., Pinder G.F. (1982), Numerical solutions of partial differential equations in science and engineering, Wiley, New York, N.Y.

Ludemann-Hombourger, Nicoud R.M., Bailly M. (2000), The VariCol process: a new multicoumn continuous chromatographic process, Separation Science and Technol., 35,1829

Mazzotti, M., Storti, G., Morbidelli, M. (1997a), Supercritical fluid simulated moving bed chromatography, J. Chromatogr. A 786, 309

Mazzotti, M., Storti, G., Morbidelli, M. (1997b), Optimal operation of simulated moving bed units for non-linear chromatographic separations, J. Chromatogr. A, 769, 3

Migliorini C., Mazzotti M., Morbidelli M. (1998), Continuous chromatographic separation through simulated moving beds under non-linear conditions, $J$. Chromatogr. A, 827, 161

Migliorini C., Mazzotti M., Morbidelli M. (1999), Design of simulated moving-bed units under nonideal conditions, Ind. Eng. Chem. Res., 38, 2400

Mihlbachler K., Anspach B., Seidel-Morgenstern A. (1998), Experimentelle und theoretische Untersuchungen der Gradientenchromatographie eines Proteins, Chem. Ing. Techn. 70, 382

Myers A. L. (1983), Activity coefficients of mixtures adsorbed on heterogeneous surfaces, AlChE J., 29, 691

Nagrath D., Bequette R.W., Cramer S.M., Messac A. (2005), Multiobjective optimization strategies for linear gradient chromatography, AIChE J., 51, 511

Nicoud, R.-M, Perrut, M., Hotier, G. (1995). Method and apparatus for fractionation of a mixture on a simulated fluidised bed in the presence of a compressed gas, a supercritical fluid or a subcritical liquid, U. S. Patent 5422007

Nicoud R.-M., Seidel-Morgenstern A. (1996), Adsorption isotherms: experimental determination and application to preparative chromatography, Isolation and Purification, 2, 1996, 165

Nicoud, R.-M. (1998), Simulated Moving Bed (SMB): Some possible applications for biotechnology, in: Bioseparation and bioprocessing, Vol. 1 (Ed. Subramanian G.), Wiley-VCH, 3-39

Nikitas P., Pappa-Louisi A. (2005), New approach to linear gradient elution used for optimisation in reversed-phase chromatograph, J. Chromatot. A., 1068, 279

Ruthven, D.M., Ching, C .B. (1989), Countercurrent and simulated countercurrent adsorption separation process. Chem. Eng. Sci. 44, 1011

Schramm H., Kaspereit M., Kienle A., Seidel-Morgenstern A. (2002), Improving simulated moving bed processes by cyclic modulation of the feed concentration. Chem. Eng. Technol., 25, 1151

Seidel-Morgenstern A. (1995), Mathematische Modellierung der präparativen Flüssigchromatographie, Deutscher Universitätsverlag, Wiesbaden 
Seidel-Morgenstern A. (2003), Preparative gradient chromatography (in Russian), Russian Chemical Journal (Journal of the Russian Mendeleev Society), XLVII, No.1 (Special issued: 100 years chromatography), 80.

Shan Y., Seidel-Morgenstern A. (2005), Optimization of gradient elution conditions in multicomponent preparative liquid chromatography, $\mathrm{J}$. Chromatogr. A, submitted

Snyder L.R. (1968), Principles of adsorption chromatography, Marcel Dekker, New York

Snyder L.R., Stadalius M. A. (1986), in Horvath C. (Editor), High performance liquid chromatography- advances and perspectives, Vol. 4, Academic Press, N.Y., 208

Snyder L.R., Dolan J.W., Carr P.W. (2004), The hydrophobic-substarction model of reversed-phase column selectivity, J. Chromatogr. A, 1060, 77

Soczewinski, E. (1969) Solvent Composition Effects in Thin-Layer Chromatography Systems of the Type of Silica Gel-Electron Donor Solvent, Anal. Chem. 41, 179

Spieker A., Kloppenburg, E., Gilles E.D. (1998), Computer modeling of chromatographic bioseperation, in: Bioseparation and bioprocessing, Vol. 1 (Ed. Subramanian G.), Wiley-VCH, 329

Truei Y.-H., Gu T., Tsai G.-J., Tsao G.T. (1992), Large scale gradient elution chromatography, in: Advances in biochemical engineering (Editor Fiechter A.), Springer-Verlag, Berlin, 47, 1

Wang A., Carr P.W. (2002), Comparative study of the linear energy relation, linear solvent strength theory, and typical-conditions model for retention in reversed-phase liquid chromatography, J. Chromatogr. A, 965, 2

Wekenborg K., Susanto A., Schmidt-Traub H. (2004), Nicht-isokratische SMBTrennung von Proteinen mittels Ionenaustauschchromatographie, Chem. Ing. Techn., 76, 815

Yamamoto S., Suehisa T., Sano Y. (1993), Preparative separation of proteins by gradient- and step-wise elution chromatography: zone sharpening effects, Chem. Eng. Commun., 119, 221

Zang Y., Wankat P.C. (2002), SMB-operation strategy-partial feed, Ind. Eng. Chem., Res., 41, 5283

Zhang Z., Mazzotti M., Morbidelli M. (2004), Continuous chromatographic processes with a small number of columns: comparison between simulated moving bed with VariCol, PowerFeed and ModiCon, Korean J. Chem. Eng., 21, 454 


\section{Table 1:}

Parameter of the adsorption isotherm model (eq. 12) for the two cycloketones (C5 and C7) (Antos and Seidel-Morgenstern, 2001).

\begin{tabular}{|c|c|c|}
\hline & $i=\mathrm{C} 5$ & $i=\mathrm{C} 7$ \\
\hline$a_{1}^{i}[1 / \mathrm{vol} \%]$ & 0.0090 & 0.0161 \\
\hline$a^{i}{ }_{2}[-]$ & 0.985 & 1.102 \\
\hline$b_{1}^{i}\left[\mathrm{vol}^{-1-b b, 2}\right]$ & 0.1903 & 0.316 \\
\hline$b_{2}^{i}[-]$ & 0.951 & 1.126 \\
\hline
\end{tabular}

\section{Table 2:}

Results of a two-step-gradient SMB experiment (Antos and Seidel-Morgenstern, 2001). Four columns of Set 2, $c_{F, C 5}=c_{F, C 7}=0.3 \%$ vol., $c_{D}{ }^{\text {mod }}=100$ vol $\%, c_{F}{ }^{\text {mod }}=0$ vol\%, $\dot{V}_{F}=30.1 \mathrm{ml} / \mathrm{min}, \dot{V}_{D}=5.7 \mathrm{ml} / \mathrm{min}, \dot{V}_{R}=16.2 \mathrm{ml} / \mathrm{min}, \dot{V}_{E}=19.6 \mathrm{ml} / \mathrm{min}$, Shift time: $2 \mathrm{~min}$.

\begin{tabular}{|c|c|c|c|c|c|c|c|c|}
\hline $\begin{array}{c}E_{R, C 7^{*}} \\
{[-]}\end{array}$ & $\begin{array}{r}E_{E, C 5}{ }^{*} \\
{[-]}\end{array}$ & $\begin{array}{c}\operatorname{Pur}_{R}^{*} \\
{[\%]}\end{array}$ & $\begin{array}{c}\operatorname{Pur}_{E}^{*} \\
{[\%]}\end{array}$ & $\begin{array}{l}\operatorname{Prod}_{R}^{*} \\
\quad\left[\mathrm{ml} / \mathrm{ml}{ }^{*} \mathrm{~min}\right]\end{array}$ & $\begin{array}{l}\operatorname{Prod}_{E}^{*} \\
{\left[\mathrm{ml} / \mathrm{ml}{ }^{*} \mathrm{~min}\right]}\end{array}$ & $\begin{array}{c}\text { Des }_{r e q}{ }^{*} \\
{[-]}\end{array}$ & $\begin{array}{c}C_{R, a v}^{m o d} \text { * } \\
{[\text { vol\%] }}\end{array}$ & $\begin{array}{c}C_{E, a v}^{m o d} \text { * } \\
{[\text { vol\%] }}\end{array}$ \\
\hline \multicolumn{9}{|c|}{ Gradient mode } \\
\hline $1.7^{\mathrm{a}}$ & $1.5^{\mathrm{a}}$ & $99.8^{a}$ & $94.3^{\mathrm{a}}$ & $0.114^{\mathrm{a}}$ & $0.144^{\mathrm{a}}$ & $63^{a}$ & $12^{\mathrm{a}}$ & $19^{\mathrm{a}}$ \\
\hline $1.7^{\mathrm{b}}$ & $1.4^{\mathrm{b}}$ & $99.4^{b}$ & $95.3^{b}$ & & & & $12^{b}$ & $21^{b}$ \\
\hline \multicolumn{9}{|c|}{ Isocratic mode } \\
\hline $0.29^{\mathrm{a}}$ & $0.14^{\mathrm{a}}$ & $99.9^{a}$ & $98.8^{a}$ & $0.055^{\mathrm{a}}$ & $0.056^{a}$ & $159^{\mathrm{a}}$ & $15^{\mathrm{a}}$ & $15^{\mathrm{a}}$ \\
\hline
\end{tabular}

* enrichments $(E)$, purity (Pur), productivity (Prod), normalized desorbent requirement (Des req) and averaged modifier concentrations $\left(c_{a v}{ }^{\text {mod }}\right)$
a simulated
b experimental 


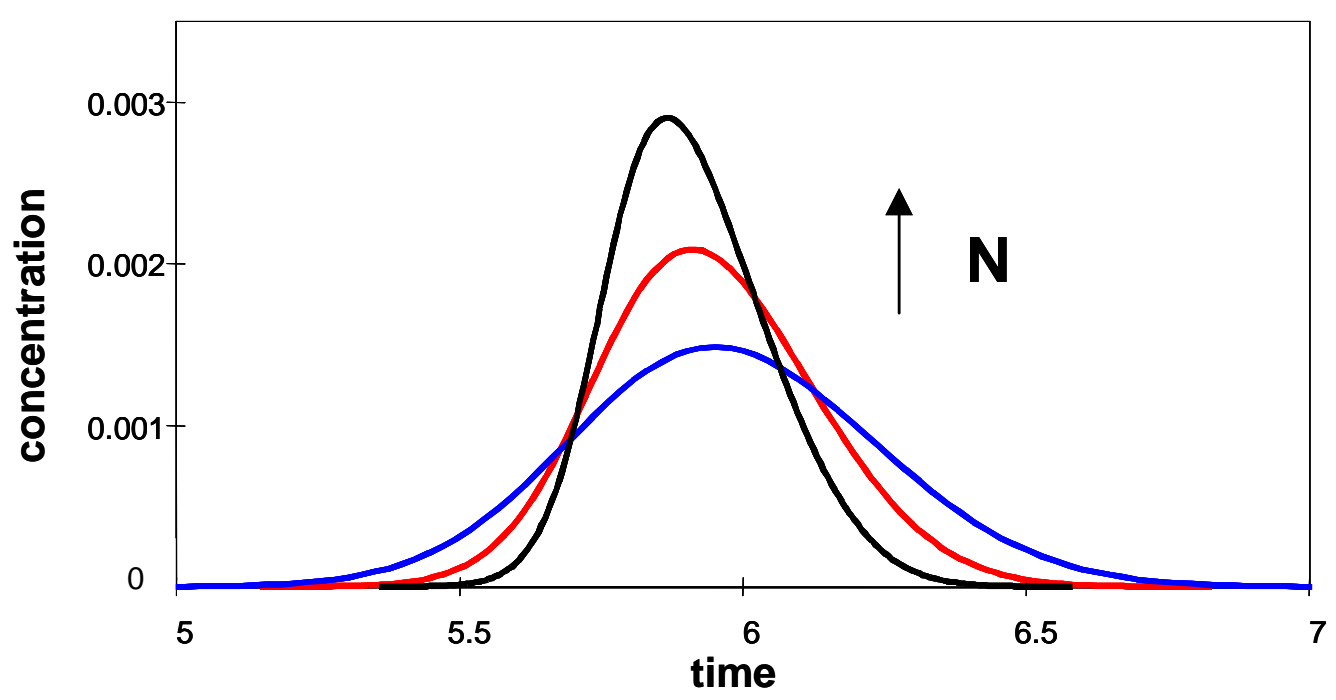

Fig. 1:

Elution profiles as a function of the plate number $N$ for linear conditions (according to eqs. 1-5). Parameters (in compatible units): $\varepsilon=0.5, u=20, L=20, a=5\left(k^{\prime}=5\right)$, Injection: $c(t, z=0)=c_{i n j}=1$ for $0<t<0.001$. Plate numbers: $N=500,1000,2000$. 




Fig. 2:

Elution profiles as function of the plate number $N$ under overloaded conditions for a single component according to eqs. 1-5. Parameters (in compatible units): $\varepsilon=0.5$, $u=20, L=20, a=5, b=5$. Injection: $c(t, z=0)=c_{i n j}=200$ for $0<t<0.001$. Plate numbers: $N=500,1000,2000$. 


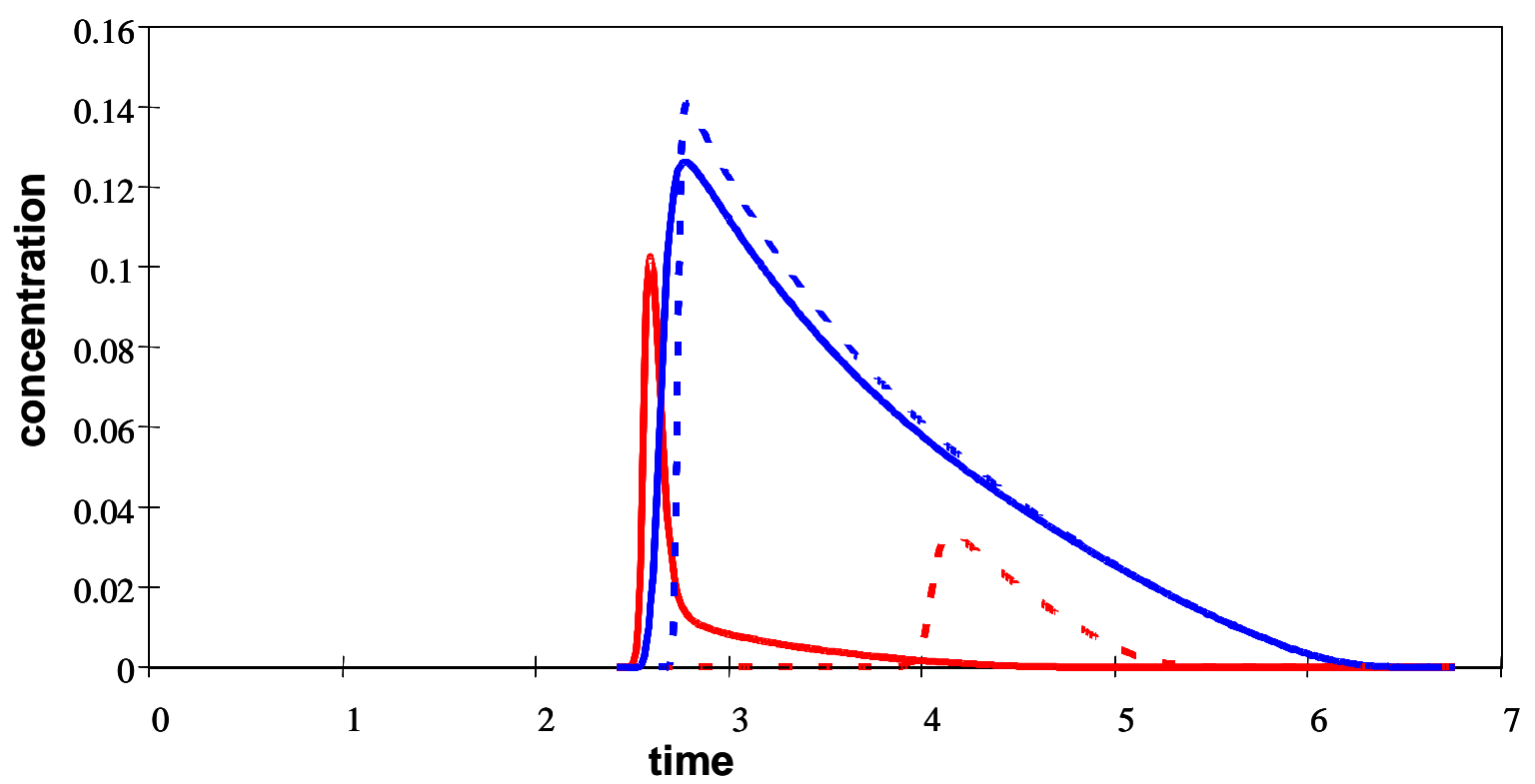

Fig. 3:

Elution profiles according to eqs. 1-5 for injections of the same amounts as a single component (dashed lines) and in a binary mixture (solid lines). Illustration of the displacement effect.

Parameters (in compatible units): $\varepsilon=0.5, u=20, L=20, a_{1}=4, b_{1}=4, a_{2}=5, b_{1}=5$, $N=1000$. Injection: $c_{i n j, 1}=20$ and $c_{i n j, 2}=180$ for $0<t<0.001$. 


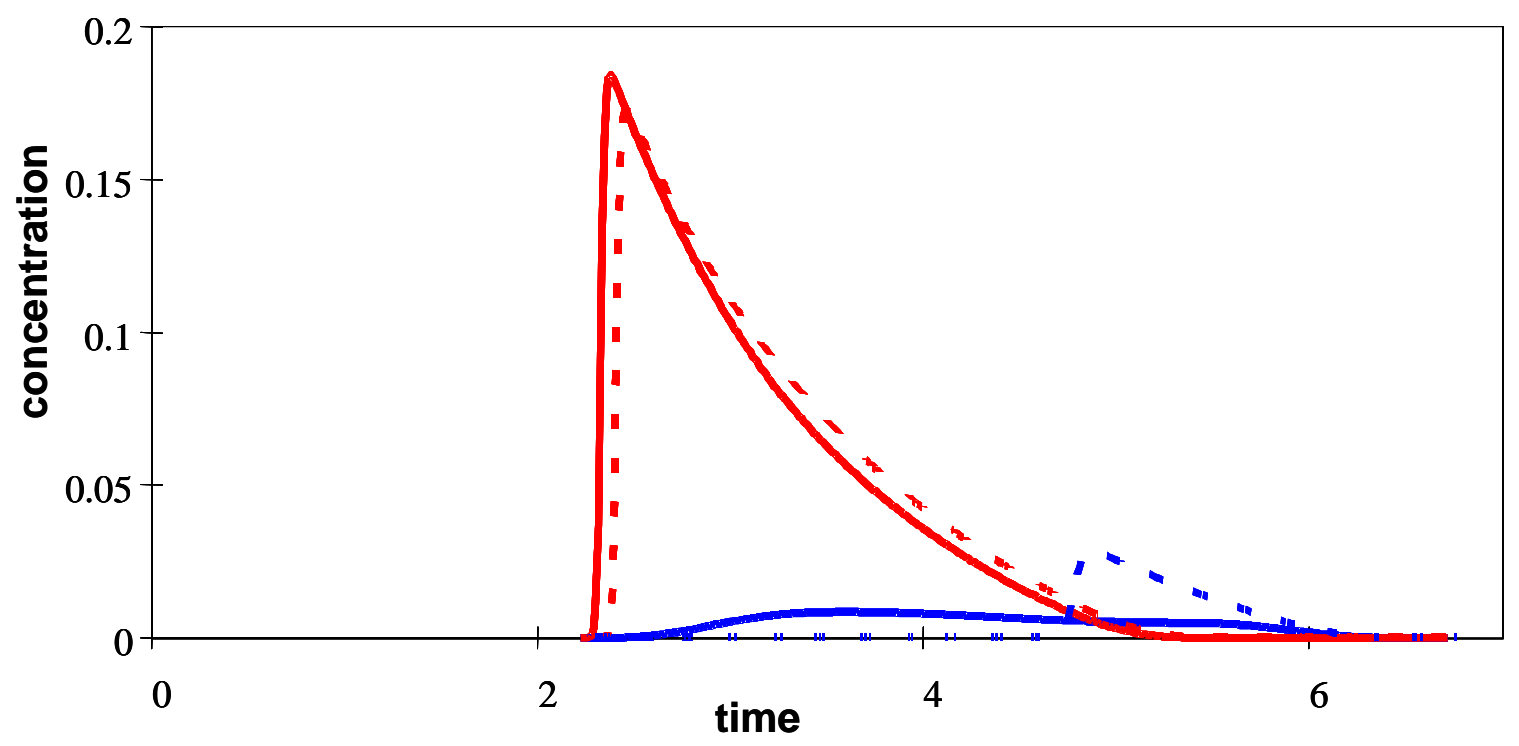

Fig. 4:

Elution profiles according to eqs. 1-5 for injections of the same amounts as a single component (dashed lines) and in a binary mixture (solid lines). Illustration of the tagalong effect.

Parameters as in Fig. 3 except: Injection: $c_{i n j, 1}=180$ and $c_{i n j, 2}=20$. 


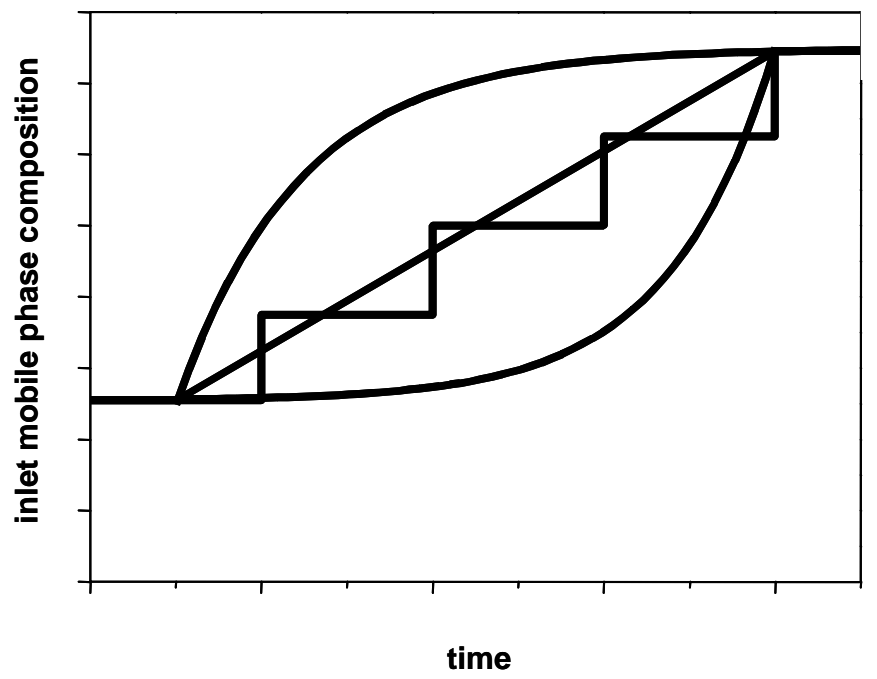

Fig. 5: Conceivable shapes of gradients. 

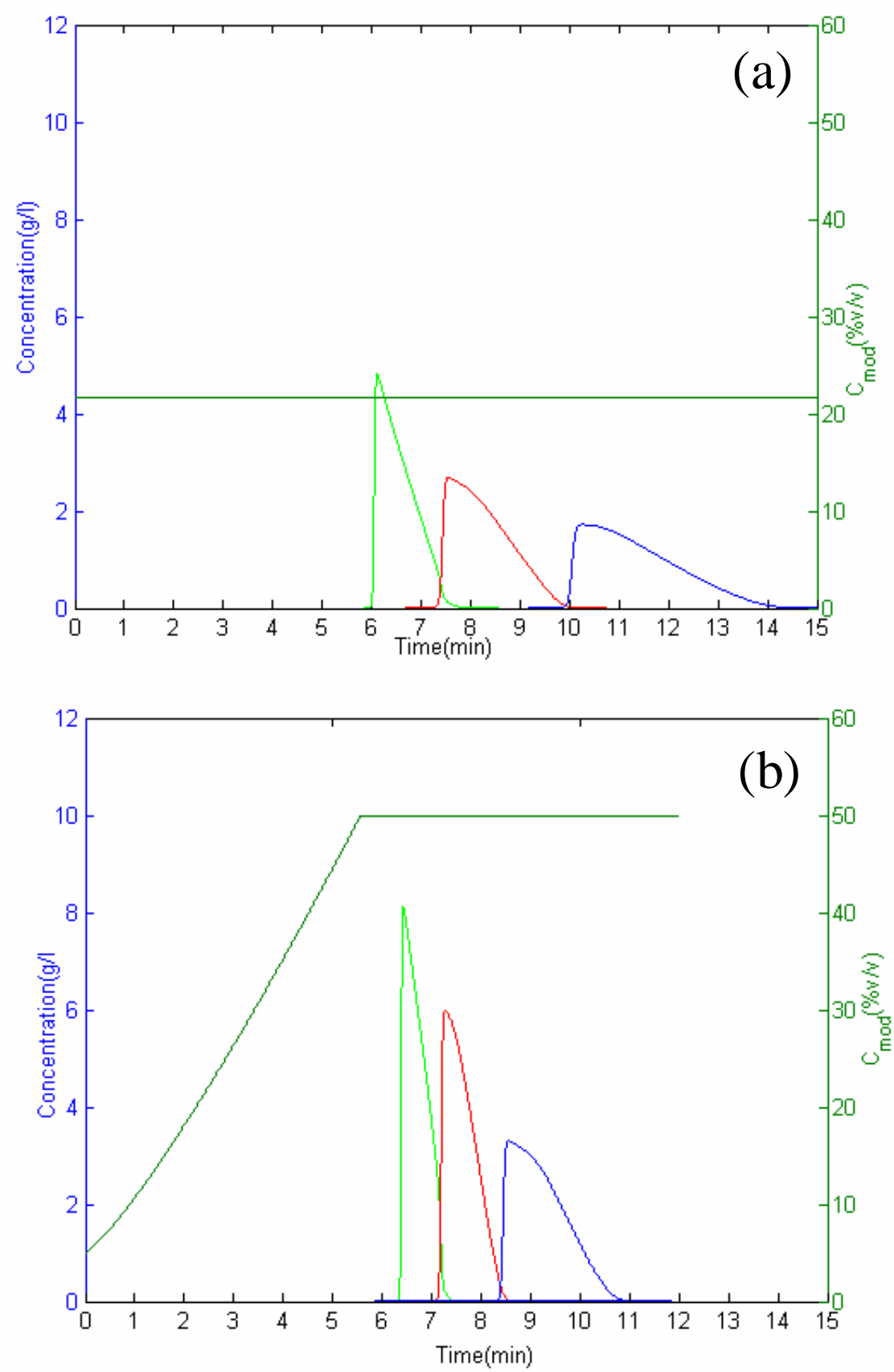

Fig. 6: Comparing isocratic and gradient operation. Both modes were optimized in order to collect most efficiently the second component of a ternary mixture. The constant or modulated solvent composition and the loading factors were the free parameters. Details are given by Shan and Seidel-Morgenstern (2005). 


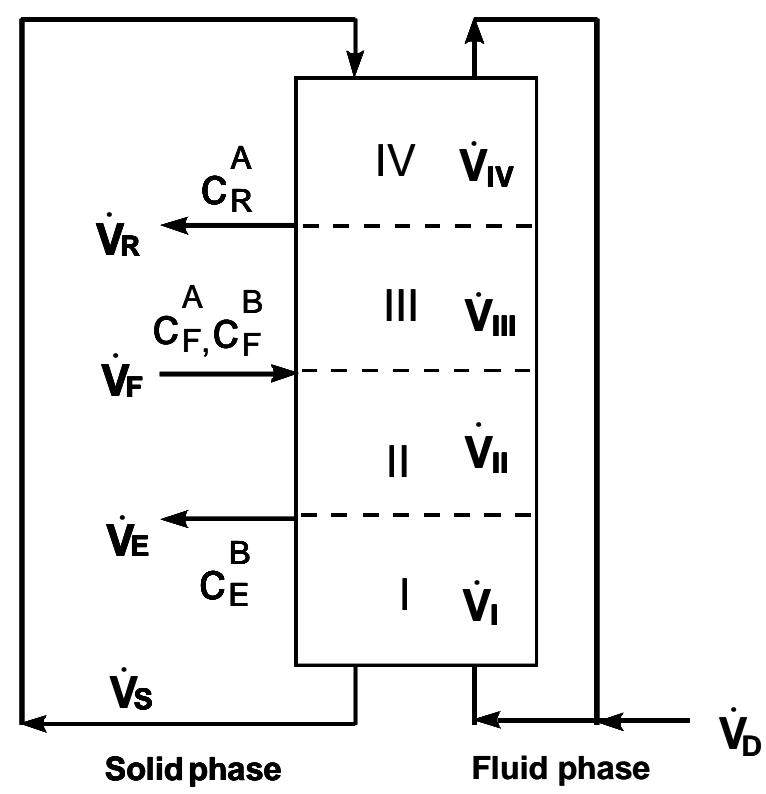

Fig. 7: Principle of a four zone true moving bed process. 


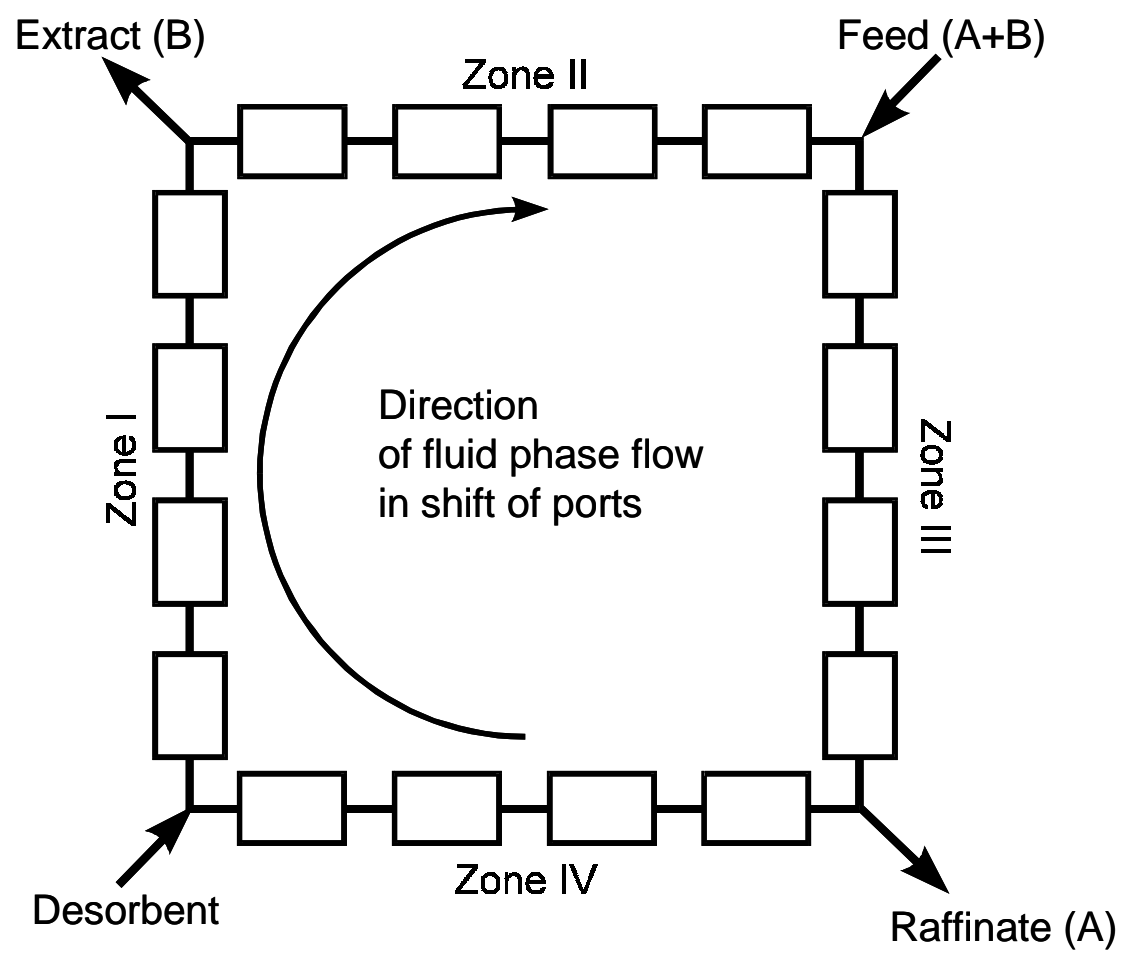

Fig. 8: Principle of a four zone simulated moving bed process. 

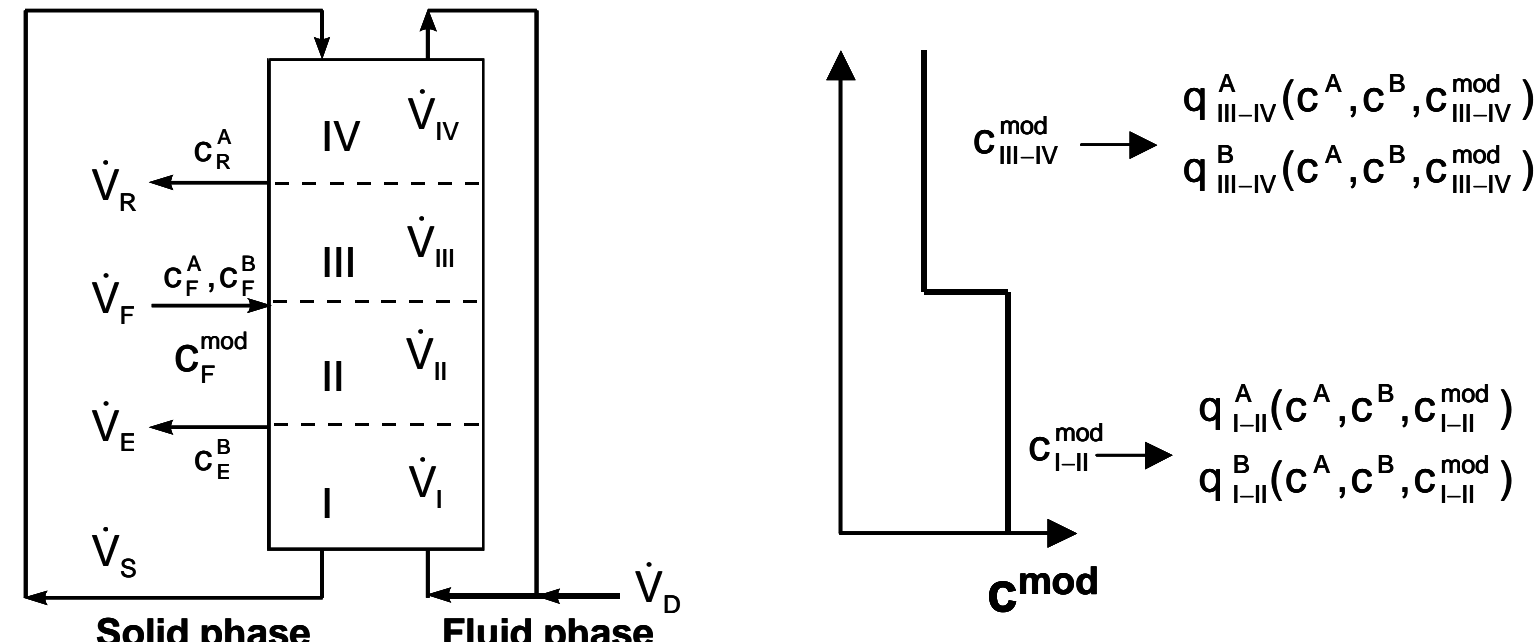

$$
C_{D}^{\text {mod }}>C_{F}^{\text {mod }}
$$

Fig. 9: Principle of a two-step gradient simulated moving bed process. 


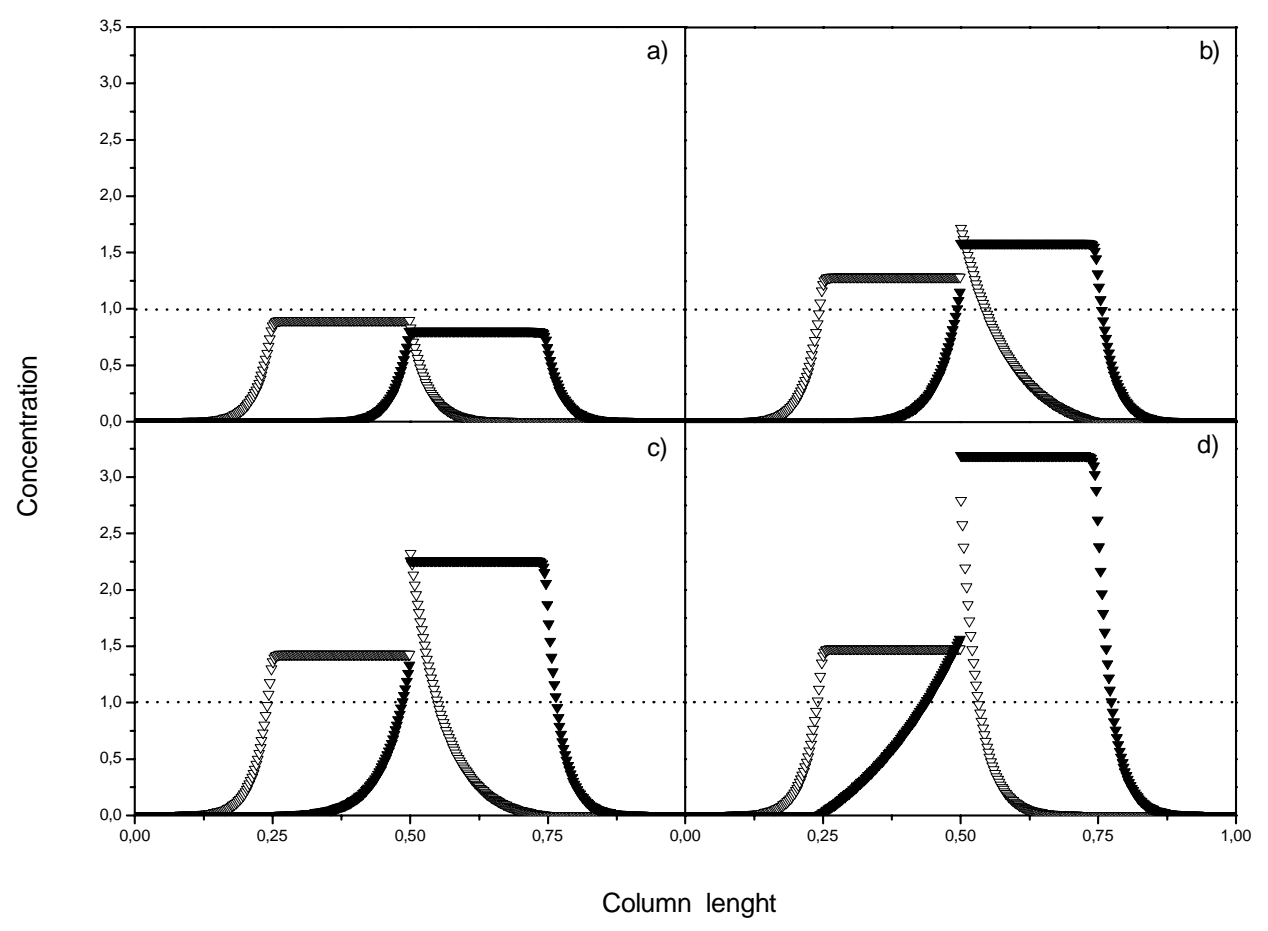

Fig. 10:

Simulated internal concentration profiles for a two step gradient countercurrent bed process for linear equilibria. Consequence of varying the flow rate ratios $m_{I I}$ and $m_{I I I}$ for constant other parameters (Beltscheva et al., 2003). a) $m_{\| l}=2.16, m_{I I I}=3.63$, b) $m_{I I}=2.78, m_{I I I}=7.01$, c) $m_{I I}=4.09, m_{I I I}=12.57$, d) $m_{I I}=8.18, m_{I I I}=30.52$. The dashed lines mark the (identical) feed concentrations. 



Fig. 11:

Single component adsorption isotherms of $\mathrm{C} 5$ (left) and $\mathrm{C} 7$ (right) at $20^{\circ} \mathrm{C}$ as a function of the modifier (ethylacetate) concentration. Solid lines: $C^{\text {mod }}=5$ vol\%. Dashed lines: $C^{\text {mod }}=10$ vol\%. Dotted lines: $C^{\text {mod }}=15$ vol\%. Parameters according to Table 1. 


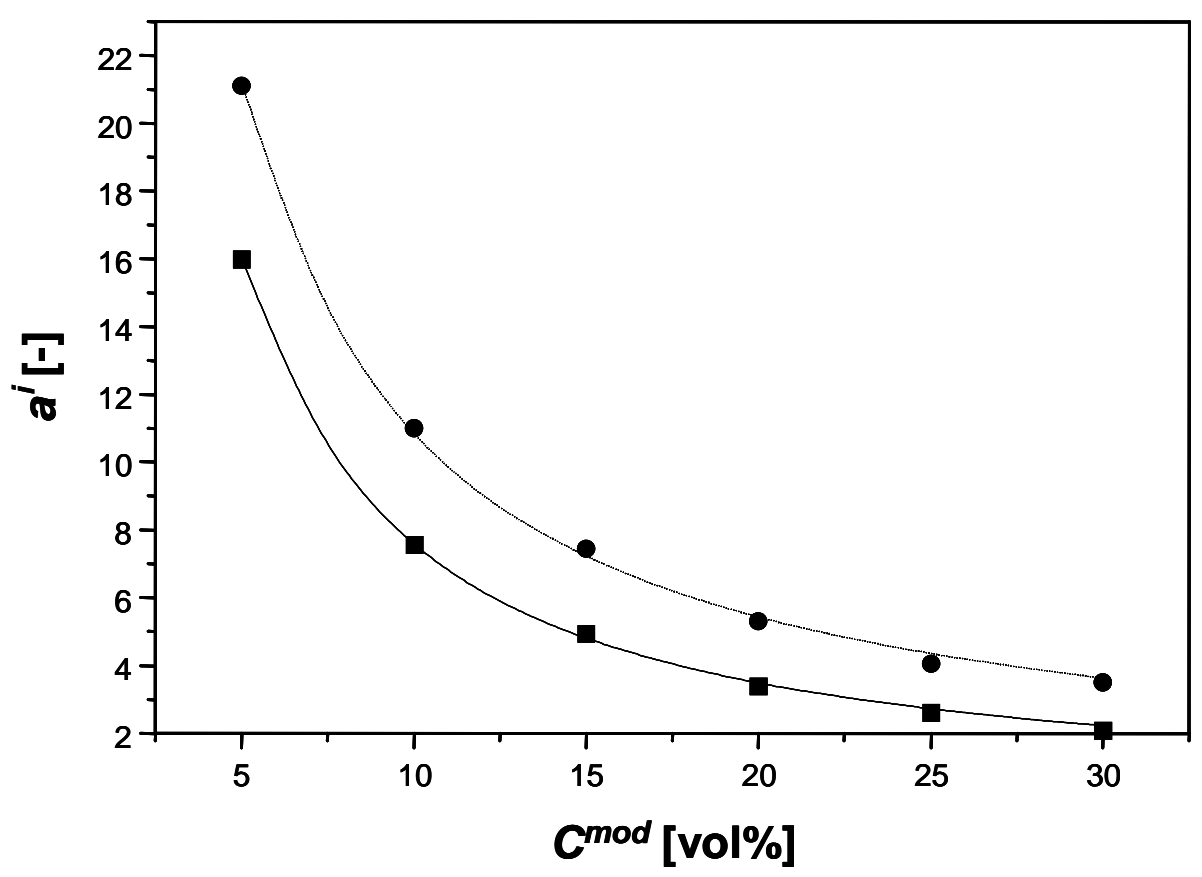

Fig. 12 : Dependence of the constants $a^{C 5}$ (circles) and $a^{C 7}$ (squares) on the modifier concentration (Parameters according to Table 1). 


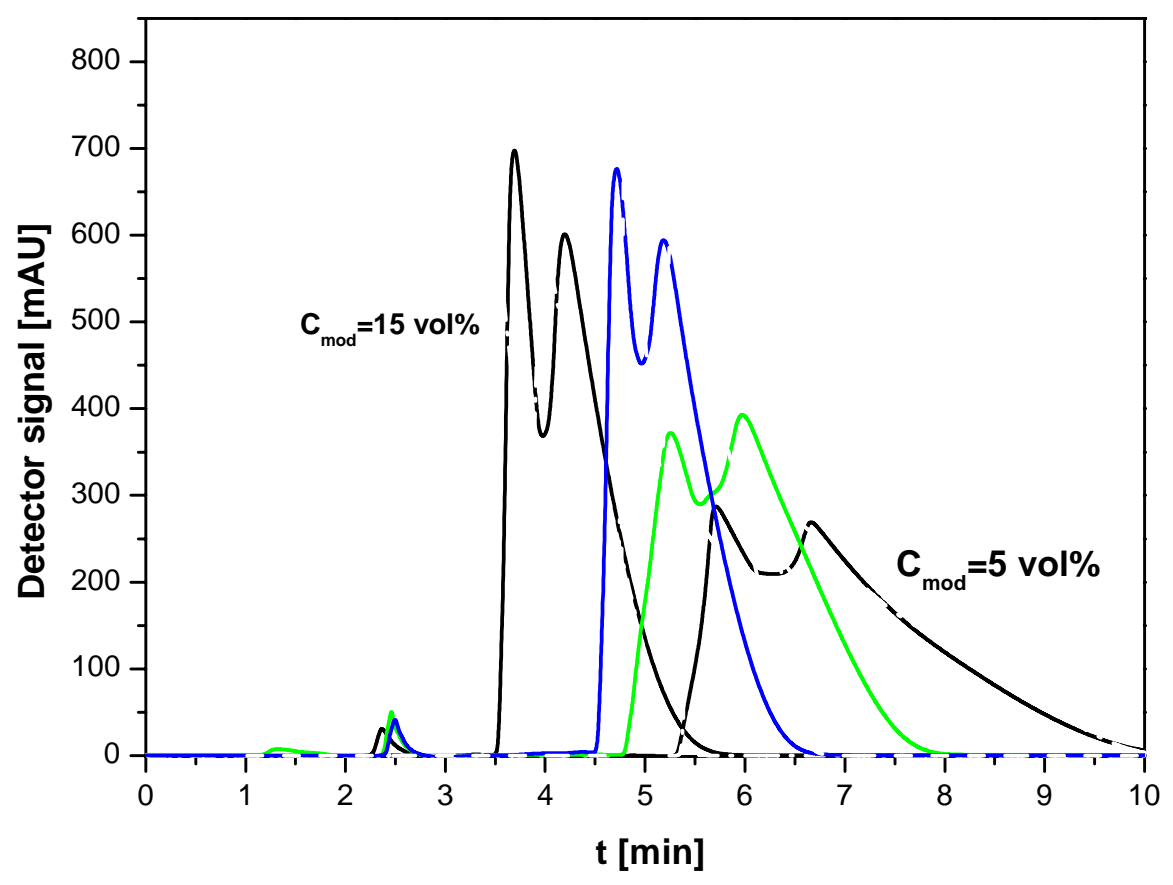

Fig. 13:

Illustration of the effect of introducing a modifier concentration gradient. First and last elution profiles: Isocratic situations for $C^{\mathrm{mod}}=5 \mathrm{vol} \%$ and $15 \mathrm{vol} \%$. Intermediate elution profiles: Linear gradients between $C^{\text {mod }}=5$ vol\% and 15 vol\% starting immediately after the sample injection with durations of 1 min and 5 min (Gueorguieva, 2005). 


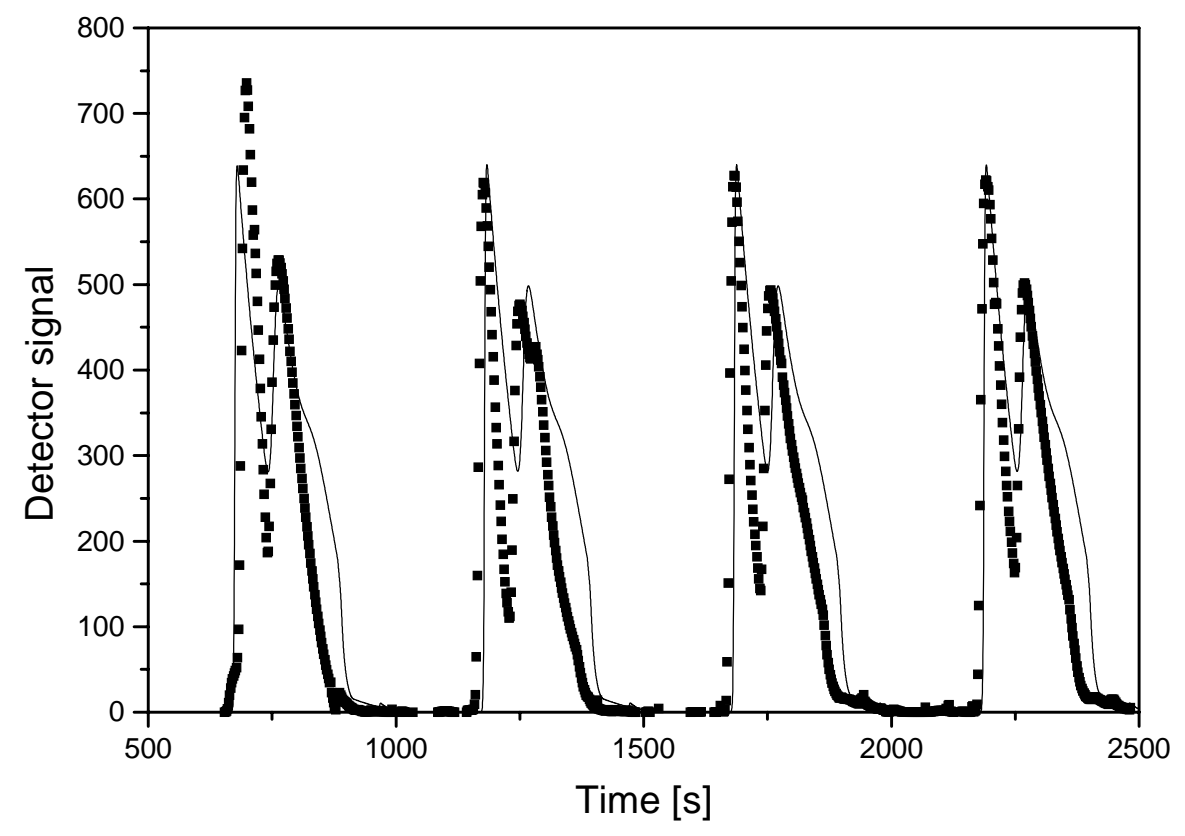

Fig. 14:

Measurements (symbols) and simulated (lines) band profiles for four cycles of a four step gradient experiment using 4 columns of Set 2 arranged in parallel. Modifier concentration steps: 5, 10, 15, 25 vol\%. Step length: 2.1 min. Flowrate in the last step twice as flowrates in the first three steps (Antos and Seidel-Morgenstern, 2002a). 


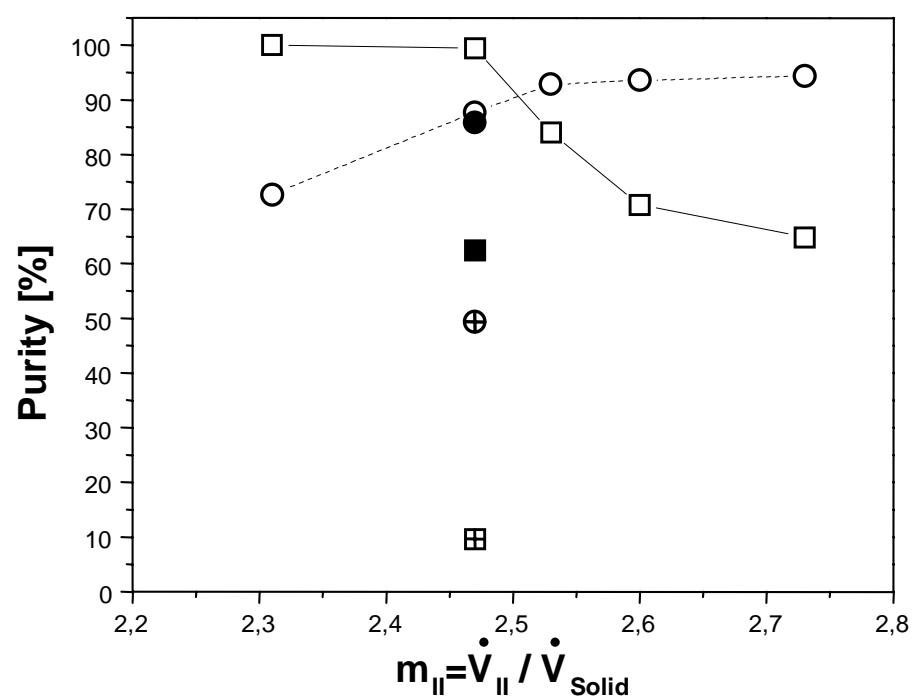

Fig. 15:

Purity of extract and raffinate outlets as a function of the dimensionless flowrate in zone II. Two-step gradient and isocratic SMB chromatography, 8 columns of Set 1 (Beltscheva 2004).

Values for the solid phase flowrates [ml/min]: $\dot{V}_{S}=0.4,0.393,0.39,0.387,0.381$.

Constant fluid phase flowrates [ml/min]: $\dot{V}_{F}=0.88, \dot{V}_{D}=4.9, \dot{V}_{E}=1.62, \dot{V}_{R}=1.59$. Circles: extract port ( $\mathrm{C} 5$ is target). Squares: raffinate port (C7 is target).

Open symbols : two-step gradient $\left(c_{\text {mod }}^{F}=15 \% ; c_{\text {mod }}^{D}=35\right.$ vol\% $)$.

Closed symbols: isocratic, $c_{\text {mod }}^{F}=c_{\text {mod }}^{D}=35 \mathrm{vol} \%, \dot{V}_{s}=0.393 \mathrm{ml} / \mathrm{min}$.

Crosses: isocratic, $c_{\text {mod }}^{F}=c_{\text {mod }}^{D}=15 \mathrm{vol} \%, \dot{V}_{s}=0.393 \mathrm{ml} / \mathrm{min}$. 